\title{
Beyond E-waste: Kenyan Creativity and Alternative Narratives in the Dia- lectic of End-of-Life
}

\begin{abstract}
:
The main focus of green IT campaigns and policy interventions in developing regions has been on efforts to counter the flows of e-waste coming from the West. This paper argues that while such interventions are necessary, they often fail to acknowledge the complexity of information-technological developments across the global South. Complementary narratives can uncover a more nuanced perception of the role played by second hand ICT equipment in development. E-waste is at first contextualized within the wider debate on the contested role of technology in post-development. Examples of the multi-dimensional role of technolog in development initiatives in Kenya are used to provide evidence of existing cultures of reuse and of their potential to inform and influence a shift in Western ICT consumption patterns, in line with contemporary debates on de-growth. Examples of alternative approaches to development in the context of ICT abound, and it's key to focus on those that have roots in the creation of value right where others would see only waste - translating the ethos of the grey economy in projects that reclaim economical and educational spaces.
\end{abstract}

\section{Agenda}

1. Post-Development, De-Growth and ICT 21

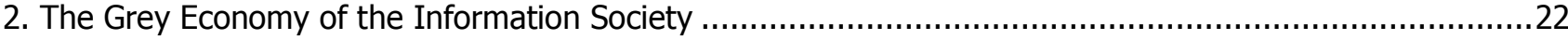

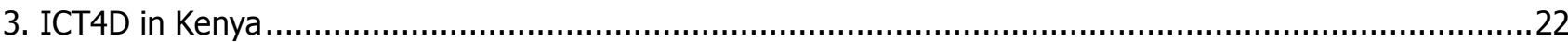

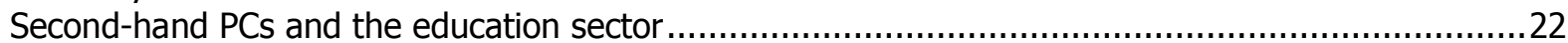

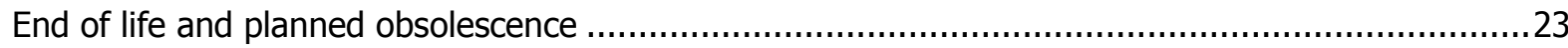

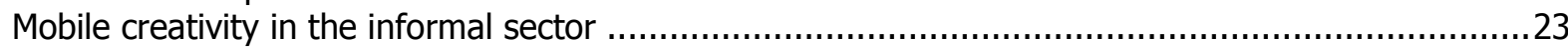

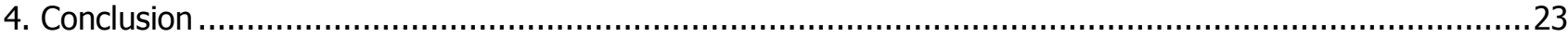

\section{Author:}

Ugo Vallauri

- ICT4D Collective, Geography Department, Royal Holloway University of London, Egham, Surrey TW20 OEX, United Kingdom

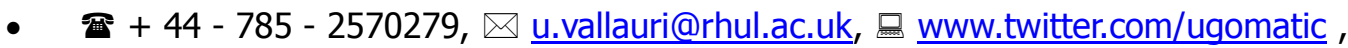
www.gg.rhul.ac.uk/postgrads/Profiles/Vallauri.html

Relevant publication:

- Vallauri, Ugo: Digitizing Kenya. Some cracks in the digital divide, in Wajibu, 24 (2), 2009 
Recent campaigns from organizations such as Greenpeace and MakeITfair have greatly contributed to increasing awareness on the environmental risks associated with the end of life of ICT equipment, the poor working conditions in the IT industry, and the serious environmental and human consequences of the multiplication of electronic gadgets in everyday life. ${ }^{1}$ As a result, in particular the discussion around e-waste has grown within both the academic and the ICT4D practitioners' community. Together with the debate came a strong and consistent visual imagery usually combining piles of dusty, old and malfunctioning desktop personal computers (PCs) in rural schools with footage of burning circuitry from discarded CRT screens in urban and peri-urban SubSaharan Africa - brilliantly exemplified by a recent Frontline PBS (2009) documentary covering the topic. The popularization of this imagery has supported reflections on the relationship between the previously disconnected geographies of IT production, consumption, and disposal. In several African countries, such criticism has already resulted in policies either completely blocking the import of second-hand IT products, as in Uganda from 2009, or severely discouraging it, as in Kenya, where the government introduced in the 2008 Budget a 25\% excise duty on all used personal computers coming from outside East Africa. Other countries, such as Zambia and Nigeria, are considering similar measures. Such decisions can partially be linked to the active lobbying of local firms and international IT corporations interested in expanding their presence in the new commercial frontiers of the emerging markets - especially at a time of progressive saturation and recession in the Western markets. ${ }^{2}$ However, these measures also clearly indicate a growing negative perception of used electronics and in particular of refurbished PCs among African policymakers.

\section{Post-Development, De-Growth and ICT}

The issue at stake is not the obvious ethical unacceptability of the illegal trade and dumping of electronic waste into countries such as China, Ghana, India, Nigeria, or Hong Kong, but instead whether the dominant e-waste-discourse on environment

1 for example, Norbrand, 2009, video and leaflets on makeitfair.org

2 Cisler, 2005 and ICT fails to explore and acknowledge other, more diversified perspectives on the use of secondhand electronic products in developing countries. But rather than contesting the validity of existing ewaste campaigns, I make the case for the consideration of a range of other narratives that take into account not only the environmental risks but also the promising opportunities associated with the full inclusion of the South in the global information society. Mapping the multi-dimensional and controversial aspects of the reuse and the recycling of IT products in developing countries is a necessary element in assessing the global ecological sustainability of ICT for development.

This need to explore alternative narratives resonates with work in the post-development tradition, briefly explored here by way of engaging Serge Latouche's most recent work. Latouche focuses on the concept of de-growth (more widely known as the French "decroissance") as the concept has proved popular in inspiring new social movements in France and Italy. ${ }^{3}$ With de-growth, Latouche takes the postdevelopmental critique a step forward, challenging Western societies to learn to de-grow from excessive consumption, GDP-driven policies, and lifestyles based on environmental degradation - a vision in line with the green IT campaigns to "use, reuse and only eventually recycle" of Western IT charities.

The use of de-growth in the context of ICT is extremely rare, apart from Schauer (2008), who focuses on the risks of the rebound effect, in particular on the contradictions between material degrowth supposedly facilitated by ICT with the progressive digitalization of all artifacts and the increased ecological footprint caused by low prices of ICT equipment and consequent high diffusion of all sorts of devices. Such a multiplication of devices is at the heart of Latouche's own critical position on technologies in the context of development - first of all in regards to current trends of introduction and transfer of new technologies, which distract from and hinder locally determined self-development strategies. This accusation of a sort of "technocolonialism" is common in post-development thought, and it refers to the imposition on developing regions of new technological solutions, designed with aims and objectives not necessarily in line with those of the regions they are pushed to. But even more importantly in this context, Latouche also condemns African "second-hand consumption societies" made of Western waste such as unserviceable

3 Latouche 2007, 2008 
mobile phones, recuperated personal computers and the likes. But by doing so, Latouche fails to acknowledge the values of informal African economies based on repair, reuse, adaptation and creativity paradoxically a theme at the very essence of the degrowth he envisions for the West.

\section{The Grey Economy of the Information Society}

Ravi Sundaram has offered a different approach, taking into consideration the fertile ground of the informal economies of Indian ICT. In Recycling Modernity (1999), Sundaram already criticizes the neoliberal vision of India as an homogenous technospace, one where all that matters is the "young, upper-caste, often English-speaking programmers in large metropoles, particularly emerging techno-cities like Bangalore and Hyderabad". But Sundaram's analysis, far from being an hymn to a nationalist rejection of new media technologies, goes well beyond a critique of the cyberlibertarian ideology of new economy hubs in developing regions - it points to the "grey economy" of hardware reuse and recycling as well as of software pirating, a flexible practice of survival for those excluded from the techno-elite, contributing in urban and rural areas alike to lowering costs of access and reappropriation of the information society. The aspects of survival and of extreme necessity linked to the grey economy are critical in explaining it as a form of resistance to the global market dynamics of ICT diffusion, clearly in opposition with a simple fascination for digital tinkering, typical of the cyberelites.

Even ten years after these reflections on the multiple levels of engagement of the Indian society with ICT, a new version of the same developmentalist ideology currently dominates ICT-debates in Kenya. Neither the Kenyan government nor major development agencies reflect positively on the demands of the grey economy and on the needs of the most marginalized groups. Instead, at a time when the completion of the first undersea fibre optic cable is finally bringing broadband to the region, the Kenyan government's ICT Board (2009) is attempting to brand the country as the ultimate Business Process Outsourcing (BPO) destination, a sort of "ultimate India" engaging with the infinite capitalist struggle for the cheapest labour. Yet despite policy responses to e-waste (the new excise duty on used IT-imports), today's Kenya can't do without used electronics.

\section{ICT4D in Kenya}

Examples of alternative approaches to development in the context of ICT abound, and it's key to focus on those that have roots in the creation of value right where others would see only waste - translating the ethos of the grey economy in projects that reclaim economical and educational spaces well beyond anecdotal evidence, offering a sustainable alternative to top-down approaches of technology transfer.

\section{Second-hand PCs and the education sector}

Computers for Schools Kenya (CFSK, www.cfsk.org), a Kenyan NGO providing Kenyan secondary schools with access to computer labs fitted with refurbished PCs, suggests a different narrative for the environmental problematic linked to ICT4D. Apart from the actual computers, CFSK provides ICT training for teachers and assistance in the periodic maintenance of the IT equipment supplied. Over the past few years, CFSK has distributed over 10,000 PCs to more than 400 secondary schools within Kenya, much more than the Ministry of Education itself has achieved, whether with new or refurbished PCs, and at a much lower cost per seat. As part of its activities, CFSK provides schools with a concrete solution for the substitution of the deployed refurbished PCs at the end of their life-cycle with newer refurbished PCs, and only installs hardware when proper facilities exist in the school, such as an appropriate classroom, security, equipment to limit risks deriving from power failures - a major problem for maintenance of both brand new and second-hand PCs in Kenya. CFSK procures its PCs both locally, through corporate social responsibility programmes of local and international companies, and internationally, through donations from IT charities, such as Computer Aid. On top of that, CFSK is a local innovator, not only because it manages to extend the life of its PCs, but more importantly because their technicians have developed a method to give a new, "third life" to malfunctioning second-hand CRT monitors, by re-engineering them into low-cost television sets. CFSK is directly involved with handling obsolete and no-longer working PCs, and has recently established an e-waste management centre, to locally recycle components whenever possible, and ship the rest out of the country for environmentally sound recycling. 


\section{End of life and planned obsolescence}

The example of CFSK also addresses another aspect of the link between information technology and the environment: the question of what is indeed the end-of-life of a product. The concept of planned obsolescence can help in shedding light on how a product is perceived as obsolete and as such loses its trading and use value. ${ }^{4}$ The case of the computer industry is a classic example. Computer processor designers are busy with the next generation even before starting distributing the current one. Software engineers, especially in the proprietary software world, don't feel compelled by the limitations of most consumers' hardware in coding their products. As a result, computers and other electronic devices' life-span is constantly artificially reduced, while new needs emerge as fabrications of marketing strategists. However, different groups of users redefine what's useful to them in resisting opposition to market logic. This autonomous way of making use of the existing resources and of adapting them to specific needs resonates well not just with a common sense desire to reduce, reuse and recycle, but also with studies highlighting how the most energy-intensive aspects of computing lie within the manufacturing process, and that therefore extending the life-span of existing computers is the most environmentally friendly option, and should be pursued at all levels ${ }^{5}$. The Kenyan government's decision to introduce an excise duty on the importation of second-hand computers in 2008, however, had a severely negative impact on the activities of organizations such as CFSK; the new excise duty is also an inadequate measure to tackle and regulate the electronic waste already existing in the country.

\section{Mobile creativity in the informal sector}

The interaction between an extended life-span, wider access to technology, and local innovation provides further evidence for reconsidering the role of used electronics. One example is that of the Kenyan M-Pesa service, the first successful widescale implementation of a mobile payment system in Africa, ahead of many yet to come implementation in more "developed" countries. ${ }^{6}$ The story of M-Pesa is peculiar because it is a technology requiring very basic mobile phones for the end users, as all money

\footnotetext{
4 London, 1932 and Slade, 2006

Williams, 2004

mobile money in Swahili
}

transfers are completed simply via SMS. ${ }^{7}$ This doesn't only imply that the technology is open to all literate mobile phone owners, but also more significantly that by being compatible with the lowest common denominator of mobile devices, "old" but reliable technology, M-Pesa has quickly become relevant to millions of Kenyans - almost 7 million users are currently registered to the service, out of 35 million inhabitants - including those relying on a second or third-hand or refurbished mobile phone. This is the kind of "pro-poor" innovation fostered by technology research and adoption in developing regions, which Heeks (2008) refers to as the engine of a new wave of more effective ICT4D 2.0. By providing an easy way to distribute micro-payments across urban and rural areas alike, M-Pesa facilitates the growth of economic and social opportunities to under-served communities, while at the same time reducing needs for travelling across the country to transfer money to otherwise "unbanked" citizens - ironically, a sort of technologically-caused degrowth.

By focusing exclusively on 'broken' mobile phones in Africa, Latouche fails to capture that in Kenya, like everywhere else on the continent, mobile phones literally never die, because of the technical expertise of thousands of meticulous workers constantly dismantling phones, studying circuit by circuit, readapting spare parts, never giving up until they learn how to fix the handset or to unlock it. But this creativity goes further: modified phones with dual SIM cards, helping to cope with poor network coverage or high interconnection fees, solar or car battery-powered mobile chargers for area not yet covered by mains electricity - the list of opportunities sought after by jua cali entrepreneurs is endless, in a constant form of struggle for the appropriation of a technology designed elsewhere and originally with the devices' planned obsolescence in mind. ${ }^{8}$

\section{Conclusion}

While it is correct to demystify the dominating hype surrounding the diffusion of ICT in developing regions around the world, it would also be shortsighted to underestimate the positive excitement generated by technology introduction in education,

\footnotetext{
Hughes and Lonie, 2007

8 'hot sun' in Swahili, it refers to thriving informal sector
} 
agriculture and every day life, and how this "magic" element can often result in surprising "unintended consequences" ${ }^{\prime \prime}$. A secondary school in Maasai Land, a semiarid rural area in the South of Kenya near the border with Tanzania, received in 2006 refurbished computers to equip a laboratory, but didn't at the time have access to electricity. This could at first be read as a classic example of a solution looking for a problem: discarding used computers to a place where they cannot be of any use. And yet, within a few months, the tangible excitement generated by the availability of computers in the local community was successfully used to lobby the local authorities to extend rural electricity to reach the school. As a result, not only the students were given the opportunity to learn basic computer skills, but - perhaps more importantly - they were also finally able to read and study after sunset.

Despite the ecological and economic constrains in which they are inscribed, African cultures of reuse and continuous adaptation and local innovation are a powerful alternative narrative tool addressing not just the ICT world, but consumer society as a whole. The understanding and appreciation of this different approach towards all waste and in particular unnecessary e-waste is critical in formulating a global ethical discourse on the multiple dimensions of the sustainable information society. The debates on the final destination of electronic waste are broadened and contextualized by such a concurrent analysis of the mechanisms behind the planned obsolescence of products, and of existing practices across the globe that can feed into visions of 'ge-growth' and sustainable forms of technological reappropriation that break this cycle. The patterns of infinite reuse and recreation of value without material production employed by Kenyan individuals and organizations offer powerful examples of what the de-growth means in the context of the information society. At a time when the system of global capitalism is showing its limits like never before, translating these inspiring examples into practices of more critical ICT consumption can help citizens and governments of developed and developing countries alike to reconfigure the myth of the global information society into more acceptable, just and sustainable terms.

\section{References}

Ali, Maryam and Bailur, Savita: The challenge of sustainability in ICT4D - Is bricolage the answer? Proceedings of the 9th International Con- ference on Social Implications of Computers in Developing Countries, São Paulo, Brazil, May 2007

Cisler, Steve: What's the matter with ICTs, incommunicado Reader, institute of network cultures 2005.

Frontline PBS: Ghana: Digital Dumping Ground, www.pbs.org/frontlineworld/stories/ghana804/, 2009

Gathara, Victor: Fibre comes East...Is Kenya Prepared?, DFID Kenya and Somalia, www.gg.rhul.ac.uk/ict4d/workingpapers/Gathero .doc, 2009.

Heeks, Richard: ICT4D 2.0: The Next Phase of Applying ICT for International Development. Computer, June 2008. 26-33.

Kenya ICT Board: Kenya BPO Value Proposition Strategy, www.ict.go.ke/pdfs/do-it-in-Kenya.pdf .2009

Latouche, Serge: La scommessa della decrescita. Feltrinelli 2007

Latouche, Serge:Breve trattato sulla decrescita serena.Bollati Boringhieri 2008.

London, Bernard: Ending the recession through planned obsolescence, 1932. In White, Micah: Consumer Society is Made to Break. Adbusters, 2008

Norbrand, Sara: Out of Control. E-waste trade flows from the EU to developing countries. SwedWatch, http://makeitfair.org/thefacts/reports/out-of-control/at download/file 2009

Osibanjo, O. and Nnorom, I.C.: The challenge of electronic waste (e-waste) management in developing countries, Waste Management \& Research 2007

Schauer, Thomas: Technology and the Growth Problematique. Proceedings of the First Conference on Economic Degrowth for Ecological Sustainability and Social Equity 2008

Slade, Giles: Made to Break. Technology and Obsolescence in America, Harvard University Press 2006

Sundaram, Ravi: Recycling Modernity: Pirate electronic cultures in India. Third Text, 13 (47), 1999

Williams, Eric: Energy Intensity of Computer Manufacturing: Hybrid Assessment Process and Economic InputCombining thods. Environmental Science \& Technology, 2004. 38, 6166-6174

$9 \quad$ Ali and Bailur, 2007 